\title{
EGOCENTRISM AS A FACTOR OF THE MANAGERIAL COMPETENCE DEVELOPMENT
}

\author{
Olga D. Polezhaeva ${ }^{1}$ \\ Vera N.Sofina ${ }^{2}$ \\ Maria P. Gabova ${ }^{3}$
}

\begin{abstract}
: the article is devoted to the study of egocentrism. The topicality of this problem is stipulated by the fact that the results of the research on human motives to determine one's ability or inability to act for the benefit of others and sacrifice one's own interests for the sake of achieving a common high goal are in high demand nowadays among specialists engaged in teambuilding at work, sport events and so on. The purpose of the article is to study reasons for the egoistic and altruistic behavior of

conducted study revealed a close relation between the person's inner attitude towards cooperation and high success rates of an individual. It was also found that the method of cybertraining allows to reveal with a high degree of accuracy the ability and inability of a participant to perform in a joint activity. The results of the study can be practically useful in business coaching, training cosmonauts and employees from other areas where successful teamwork plays a key role in achieving the organization's goals.
\end{abstract} a person, as well as identify tendencies for a particular behavior with the help of modern technologies. The leading method to investigate this problem is cybertraining, the application of which makes it possible to identify the motivation of an individual to achieve common results in teamwork, as well as the influence of internal and external factors on this motivation. The

Keywords: Egocentrism, egoism, altruism, psychoanalysis, reason, personality, cybertraining, cooperation, coordination, collaboration, good teamwork, leadership, managerial competence, personal development.

Egocentrism is the quality intrinsic in every person. Usually it is attributed with a negative characteristic,

\footnotetext{
${ }^{1}$ North-West Institute of Management, branch of RANEPA, Saint-Petersburg

${ }^{2}$ North-West Institute of Management, branch of RANEPA, Saint-Petersburg

${ }^{3}$ North-West Institute of Management, branch of RANEPA, Saint-Petersburg
} 
while personality psychology claims that Ego is the basis of the very existence of man and is responsible for maintaining two most important needs of the living being: self-preservation instinct and reproductive instinct.

If one depicts a triangle, these instincts will be located at its base, with the human ego being at the top.

\section{Discussion}

In modern science the concept of "egocentrism" is used much more often than "egoism", which is more common in everyday communication and fiction. Issues related to egocentrism are considered, first of all, by psychological sciences, especially concerning the study of speech in the process of personality development. A child is almost always in the egocentric position; therefore, his speech is egocentric. Jean Piaget, a Swiss psychologist, stated that a child never aspires to stand in the place of the interlocutor, declares only his views and needs, and therefore his speech is selfcentered. The very essence of a small person existence is his physical wellbeing, so he perceives the environment as a continuation of his individual physical self.
Piaget suggested introducing a coefficient measuring egocentric speech, or E.S. It is a fraction where the egocentric speech is the numerator, and the spontaneous speech is the denominator. The value of the coefficient is affected by the level of the child's activity, as well as what kind of relations he has with adults and peers. When relations are unstable, and the child is mostly on his own, the value of the E.S. coefficient increases. As a rule, the highest rate (up to $75 \%$ of spontaneous speech) is observed at the age of three, by the age of six it begins to decrease significantly, and after seven it is mostly not observed. However, if authoritarian, command style of communication with adults takes place, egocentrism in speech can increase. And, on the contrary, among peers, where different Egos are equal, the level of egocentrism in speech decreases.

L.S. Vygotsky defined egocentric speech as speech "for self". He claimed that with age, it does not disappear completely, but transforms into inner speech, or inner dialogue. Without this inner dialogue, which reflects the person's experience of the outside worlds, it is extremely difficult to develop intelligence, and personality. 
Jean Piaget noted that egocentric speech is a sign that people do not fully understand their importance and their unique opportunities. Therefore, theyextrapolate their subjective ideas to the environment. Personal vision of the world is obvious, since each person has his own unique history of life. Sensations, perceptions, emotions make this vision purely individual. When communicating with other people, a person can find some common points, but this does not compensate for his personal life experience; experience that does not leave a person throughout his life, although it changes with selfdevelopment, self-knowledge, selfrealization in the society, i.e. during mental development.

Before the time psychology was defined as a scientific discipline, N.G. Chernyshevsky used the concept"reasonable egoism".

This term was invented as a more positive variant of the usual "egoism", which in most cases and for most people has a negative connotation. The egoist is focused only on himself and does not care about the interests of the people around him, whereas the rational egoist understands that such behavior is unfavorable, useless and imprudent.
Consequently, a reasonable egoist can take into account his own needs and interests but does not affect the needs of others at the same time. Obviously, the question arises Is such behavior selfish?

The concept of "reasonable egoism" became especially popular after the publication of the novel "What is to be done?" written by N.G. Chernyshevsky in 1863 [11]. Russian thinker, scientist, author, critic and supporter of revolutionary democratic ideas, elaborated the theory of "reasonable egoism" in his works. Egoism, in his opinion, serves as the basis for noble behavior of a person. In his work "The Anthropological Principle in Philosophy", he puts that "a man acts the way he likes to, chooses what is convenient, what tells him to give up a lesser benefit or less pleasure for more profit, more pleasure; only then the maximum benefit is achieved" [12, $\mathrm{p}$. 116]. Striving for personal benefit, N.G. Chernyshevsky believes, is intrinsic in human nature and a very important feature.

However, common benefit, according to the author, is much more important than personal egoism. "The common humanity interest stands above the benefits of a particular nation, the 
common interest of an entire nation stands above the interests of a separate class, the interest of a bigger estate is above the benefits of a smaller one" $[12$, p. 214].According to the writer, a person should always understand what is more important and this kind of understanding should define his behavior. Every action, according to this idea, must be carried out in the interests of the common benefit; in this case it will be considered a virtue. Consequently, N.G. Chernyshevsky's reasonable egoism is based on a person's understanding of the advantages of the common advantage over his own, exclusively egoistic.

A question may arise: if a person sets other people's wellbeing above his own, and also makes efforts to achieve this well-being, what is the difference between reasonable egoism and altruism?

In his concept, N.G. Chernyshevsky aimed to combine egoism and necessary interaction of people within a society. He suggested developing such a social system where people's relationships are under the control of the mind, and person's interests inspire a person to be ready for heroism and self-denial for the better good of the society. In fact, N.G.
Chernyshevsky's theory equals rational egoism and altruism.

However, in everyday discourse, altruism, as a rule, is completely opposed to egoism. Altruism is understood as readiness to serve people without any self-benefit, i.e. sacrifice for the others' well-being. Altruism as a term was proposed by the French philosopher and sociologist A. Comte. He opposed altruism and egoism and claimed that an altruistic person acts for the benefit of the others rather than for his own good [3, p. 584-586].

Nowadays the differences between egoism and altruism are just as obvious, and the problem of egoism and altruism is as relevant as 150 years ago. Modern psychological sciences introduce the concept of the biopolar continuum "egoism-altruism", where egoism and altruism are two opposite states which a person has simultaneously. In fact, one can observe a large variety of how egoism is manifested. These include narcissism, hedonism, already mentioned reasonable egoism and reasonable altruism. What exactly a person chooses depends on his level of self-development.

Egoism as a concept was also considered by the N.G. Chernyshevsky's 
contemporary, Russian writer I.S. Turgenev. In his novel "Rudin", 1856, he presents a classification of egoists, given to the reader by one of the heroes of the book, African Semenovich Pigasov: "There are three categories of egoists: those who live and let others live; those who live but do not let others live; finally, those who both do not live, and do not let others live. Women mostly belong to the third category" [7, c.213]. Despite some chauvinism expressed by Pigasov, this classification is worth studying. Any of us will easily accept the "egoist" who lives and does not interfere with others. This idea relates to the concept of reasonable egoism. The situation when a person lives only for himself, without letting others live, is a classic manifestation of egocentrism. Women raising children can be attributed to the first category of egoists, while managers who abuse their position to tyrannize their employees belong to the second type.

The third kind of egoists are mostly lonely people. They often set high demands to themselves and others, which makes it difficult for them to communicate with other people regardless of gender, which we see by the example of the hero of the novel,
Afrikan Pigasov. This behavior is typical for lonely women who could not create a family. In most cases they try to express their frustration by behaving aggressively towards men. Another example is the men who grew up surrounded by the excessive care and overprotection of mothers and sisters. They grow narcissistic and have no sincere feelings for anyone else. I.S. Turgenev speaks about this with the words of his hero, Rudin: "Rudin started talking about self-esteem, and spoke very sensibly. He argued that a person without vanity is worthless, since it is the only thing that can move the Earth, but that at the same time he deserves the name of a man who knows how to master his pride, as a horse rider, who sacrifices his personality for common good ... Selfishness", he concluded, "is suicide. The selfish person withers like a lonely, barren tree; but vanity, as a longing for perfection, is the source of all the great...Yes! A man needs to break through the stubborn egoism of his personality in order to give it the right to express itself!" [7, c.226].

However, one must understand the difference between vanity and selfishness. Vanity, to a certain extent, is a positive quality, since it stimulates the 
self-development, while selfishness, on the contrary, restricts any development, since a person is stuck on himself and accepts nothing but his personal interests.

By the end of the 19th century, the mind and consciousness of man became one of the most studied topics in psychology as an independent scientific discipline. Psychology tried to explain scientifically and demonstratively the role of awareness and egoism in the life of an individual and society as a whole. For this reason the concept of egoism appears in many scientific works of that time. The German philosopher A. Schopenhauer wrote: "I and egoism are the whole: if the latter disappears, then, in fact, there is no former" [2, p. 120].

The practice of psychoanalysis advanced in the study of egoism. One of the leading psychoanalyst scientists, the Austrian psychiatrist Sigmund Freud, examining his patients, drew attention to the fact that some of them could not consciously control their emotions. This led him to the conclusion that something "unconscious" appears in the psyche of people and plays a significant role in their lives. According to his theory, in the psyche, one can observe three phenomena: I (Ego), Super-I (Super-
Ego) and IT (Id, the unconscious). Id is a manifestation of pure egoism a person is already born with, which makes him constantly strive to obtain pleasure and satisfaction of his desires. By the age of five, Super-Ego manifests itself, begins to differentiate between the good and the bad, and performs a limiting function. Ego is in the search for a permanent compromise between Super-Ego and the unconscious. These three phenomena, according to $\mathrm{S}$. Freud, have a very strong influence on the personality. Under normal conditions, they appear rather cohesively and do not contradict significantly. According to S. Freud, we can assume that the Id reflects the biological level of a person, Ego is its psychological level, and the Super-Ego is a social level. [8].

Further, the American psychologist E. Berne, one of the adherents of the theory of S. Freud, advanced his theory of sub personalities, according to which there are three hypostases in the human psyche: The child who manifests himself through desires, emotions and needs, the Parent, with his inherent disposition for orders, rules and restrictions, as well as the Adult, responsible for predictions, conscious behavior and logic [1]. 
The Parent reflects the collective experience and traditions, he seeks to limit all feelings and actions with certain rules and norms that have been practiced for centuries. The key concepts of the Parent: it is good, it is bad, you can do that, you cannot do that, you must, you have to, etc. The Parent always relies on experience and is confident that he is right, so he is not argued with. The Adult prefers using his mind. Before making a conclusion of what is right and what is not, he carefully analyzes everything himself. He is always independent in his behavior, and this gives him the opportunity to take his role in a dialogue. The Child is guided only by two rules in his life: I want and I do not want, he is impulsive, tends to show emotions spontaneously, take offense and is very capricious. Unlike the sub personalities of the Parent and the Adult, the Child is much more self-centered and focused on himself and his needs.

In general, E. Berne's ideas are reflected in the theory of "SME" by N.N. Obozov [5]. In ancient times, philosophers put forward their theories, basing them on their personal observation and reflection on the world around them. Due to continuous practical observation and analysis, they managed to distinguish three basic components of human behavior: cognitive (thinking), affective (emotion) and practical (action); these components are especially evident in interpersonal communication. According to what components dominates human behavior, one can talk about three types of personality.

The first type (cognitive) is more focused on the study of external and internal reality. The second (emotional) is mainly interested in communicating and interacting with other people, for the third (practical) type activity and its successful completion come first.

To denote these types, the concepts "Thinker", "Interlocutor and “Doer" are used. Apparently not every person can be attributed to a certain pure type, but one can identify prevailing behavior. High study achievements and tendencies to speculate characterize the Thinker, the desire to communicate and be in constant interaction with people is peculiar to the Interlocutor; the Doer prefers to act and change the environment and does it very effectively. Since the Thinker mostly speculates, he is constantly concentrated on his inner world, and is not characterized associable or willing to control 
something. It is much easier for the Interlocutorto establish contacts, he knows how to charm, looks trustworthy, appreciates a friendly atmosphere and, as a rule, has an excellent sense of humor. The Doer is always busy with activities, completes his tasks, likes distinct goals and clear tasks that require him to be determined. Unlike the Thinker, he does not tend to speculate a lot, however, he can successfully organize and control others. This type of people also has an adequate self-confidence that allows them to perform speech in front of large audiences.

The theory of E. Berne and SMEs of N.N. Obozov are similar in many aspect sand even complement each other. The Parent is similar to the Doer in his qualities and functions, the Child is more of the Interlocutor, and the Adult is certainly the Thinker. A deeper analysis help underline the connection between $\mathrm{S}$. Freud's psychoanalytic classification of Super Ego, Ego and Id with E. Berne's theory. Super-Ego respects rules and orders, which puts it in the Parent's position. The Adult is more a reasonable egoist, he has the functions of Ego. The child with his spontaneous emotionality and self-focus is Id. SME theory places a greater emphasis on the psychology of man as a whole, without reference to its rational and instinctive components, as psychoanalysis does, however there are some obvious parallels of these theories.

All the concepts discussed above have common idea that egoism is a natural and integral part of human nature. S. Freud in his work "Interpretation of Dreams" wrote: "The child is absolutely selfish, he intensely experiences his needs and irresistibly seeks to satisfy them - especially against his rivals, other children and mainly against his brothers and sisters $[9$, p. 66]. At the same time, Freud argues that there are some factors when at an early age "altruistic desires and morality wake up in a small egoist" $[9$, p.68].

American psychologist, an adherent of humanistic psychoanalysis, E. Fromm, also addresses the study of altruism and egoism. In his work "Man for Himself", 1947, it is said that nowadays in the western countries one can see a discrepancy between the "prohibition for being egoistic" and a real life where "egoism is the most powerful and justified stimulus of man, and, following this imperative stimulus, the individual makes the greatest contribution to the common good" $[10$, p.114]. In other words, a person is asked 
to make a difficult choice: "either love others, which is virtuous, or love yourself, which is sinful" [10]. E. Fromm believed that this imposed opposition leads to a serious disbalance in the person's soul these days, because love for oneself and love for others do not necessarily have to exclude each other. E. Fromm was convinced that "modern culture inconsistency lies in distorting the meaning of personal interest rather than in egoism or individualism principles. It is not that people are too focused on their personal interest, they rather "do not love themselves" [10, p.121].

H. Selye, a Canadian scientist, the founder of the theory of the adaptation syndrome, in his work "Stress without distress", 1956, introduced the term "altruistic egoism" as an attempt to find a compromise between egoism and altruism. He states that "altruism can be viewed as a modified form of egoism, collective egoism, which helps society generate nobility. Encouraging other people to wish us good for what we have done for them, and, probably, what we will do, cause positive emotions. This is perhaps the most human way of ensuring public security and sustainability. It eliminates the gap between selfish and self-sacrificing impulses” [6, p. 21].

To sum up the abovementioned, it can be said that both egoism and altruism, despite their seeming contrast, can coexist, moreover, they both are different expressions of the same characteristic. Any action dictated by altruistic motives is useful for those who it was committed for, as well as for those who committed it. The study carried out in 1993 by A. Omoto, D. Clary and M. Snyder proves this statement. The scientists studied the motives of volunteers who helped AIDS patients. They tried to determine what motivated these people to take care of the seriously ill ones. The study revealed that, apart from obvious moral and ethical reasons, volunteers also sought to gain some professional experience that would help them advance in their careers, some wanted to improve their self-esteem and reduce the feeling of guilt, for many it was important to belong to the group and get approval of other people. [4, p. 589]. Although the desire to benefit people and act according to inner beliefs plays an important role when making a decision to become a volunteer, it is obvious that the altruism of these people also has some selfish motives. This again reminds 
us of the theory of rational egoism, which calls for action for the benefit of others, as well as for self-benefit.

\section{Materials and Methods}

Nowadays, the issues of egoism and altruism are not only theoretical, scientific, but also of purely practical interest. The results of the research on motives which encourage a person to put aside his personal interests in order to achieve a higher common goal are on high demand in modern business coaching. One of the most acute issues in building a successful business is the issue of team building and improving teamwork efficiency, increasing motivation of each employee for better cooperation within the working team. The experience of using cybertrainings as a method to identify a person's ability to work together to achieve a team goal is quite telling.

Everything old is new again. In the late 70s cosmonauts of the Star City were trained according to the medical and psychological, and sociopsychological programs. The section of the socio-psychological program presupposed the use of cybertraining to activate the state of wakefulness among cosmonauts working in the mode of continuous multi-day activity. Since it is well known that the circadian rhythm of the human body indicates a decrease in activity from 3 to 5 in the morning, for that time cosmonauts preferred cybertraining among all types of activities.

By invoking the communication process to solve common problems, cybertraining increased efficiency in the following hours of work in an individual mode. Namely, ritualizing communication during cybertrainings helps improve well-being, activity, mood, which is regarded as a subjectiveobjective factor of labor efficiency.

While ordinary computer games, played by employees without enough workload, keep player's attention on competition and individual achievements, cybertraining makes them cooperate. Here comes another type of motivation, another process and most importantly, different results are obtained. Time and accuracy, as is known, are objective criteria for assessing both individual and group work.

In the pre-computer age, time was "killed" in different ways; people simply communicated and played, using dominoes, chess, maps; they were often 
engaged in either professional or spiritual activities. Now the computer divides employees. However, the need for communication remains, and people turn to psychologists and psychoanalysts, fortunetellers and psychics. After all, personal problems have not disappeared or decreased greatly, and both competition and material possessions call for individualism. One does not really want to share possessions...

Now, 40 years later, this method of increasing labor efficiency has taken on a new lease of life in other spheres. Firms interested in maintaining a favorable climate and collaboration use cybertraining technologies. St. Petersburg, Moscow, Minsk, Kiev, Ivanovo, Murom, Finland and even Costa Rica are the cities where cybertraining technologies are being applied to the working process.

The main idea of such trainings is the following. One can objectively determine the success of any teamwork with the record of the time spent and its accuracy with the use of a relatively simple and cheap hardware device.

If in numerous and diverse trainings, role-plays and business games, the time for solving a task can be determined with the help of the ordinary watch, then the quality of work is eyeball estimate, e.g. like in figure skating.

Cybertraining gives an objective assessment. The participants of the game can be given various instructions on the cybernetic machine, but the main goal of the acivity is: "In front of you there is a device that allows you to determine the group effectiveness (compatibilitycollaboration). Using the handles, stretching them, you have to keep the "engine" on the track so that it does not touch the edges of the path. In case of the failure, i.e. poor coordination of actions - the signal indicating an error lights up. Your task is to coordinate your actions and bring the engine from point $\mathrm{A}$ to point B. One should work as quickly as possible, making minimum mistakes.

The integral indicator of the success of work (Q) is calculated with the formula:

$\mathrm{Q}=\frac{\mathrm{t}_{\mathrm{o}}-\operatorname{tgp}}{\mathrm{t}_{\mathrm{o}}}+\frac{\mathrm{O}_{\mathrm{o}}-\mathrm{Ogp}}{\mathrm{O}_{\mathrm{o}}}$

where, $t_{o}$ is the average time spent on the task for the general, i.e. known standardized sample (it is attached to the instruction), tgp is how much time this group spent on the task, $\mathrm{O}_{\text {。 }}$ is the average number of errors (attached); Ogp is the number of errors made by this group. 
An integral, balanced indicator of success can help compare groups of employees, joined together for different reasons. The simplest way is to suggest creating groups independentlyon the basis of affection or another reason. One can also try real motivation in the form of material or moral reward? In the first case it can be a game for money or other material value. In the second - moral and psychological reward.

In the Soviet time playing chess at work was even encouraged, because then there was no motto "Time is money", as is now. There was a schedule of chess games on the wall, with victories and defeats among employees; victories were celebrated. There were champions who compensated for their failures at work with chess victories. The same is now done by firms that have adopted cybertraining. As you know, the number of pair combinations in a staff can be quite large. If a group is larger, the number of combinations decreases. This is how "spontaneous socialization" takes place, interaction is more intense than in ordinary small-talk communication.

One can teach participants to understand what happens within the group when there is a common goal and how to build an optimal relationship.
Before the start of work, with the agenda of daily duties, a ritual training is offered to identify working groups, their compatibility and success orientation.

In addition to the success rate (Q), it is possible to distinguish leaders and followers, which depends on both physical states, type of activity, mood, repeated situations during teamwork in different combinations of people (pairs, triples, etc). This is a kind of indicator of the activity and skills of leaders and followers. Of course, in well-known designer firms, as before, there will be more leaders, and they are more sophisticated. But also for this case we have a matrix version of the cybernometer.

The matrix version presupposes working together to define a coded letter. Just like when working on the path, the participants of the game must move the engine along the matrix $(5 \times 5=25$ elements) to determine the letters of the Russian or Latin alphabet. The letters are coded in such a way that the field of this matrix must be guessed by light or sound signals. To complicate the task, it is possible to change the outline of letters by turning the base of the letters.

The task itself is to determine the letter as quickly as possible and with a 
minimum number of verification elements. The roles will be distributed in such a way that someone will take organizational responsibility. Another participant would prefer the recording of hypotheses of a possible letter. The complexity of the letters is different, but there are such nodal points which most letters have. Identification of the relevant elements of the letter outlines is the heuristic way of solving the problem. The time and number of verification moves are fixed and the $\mathrm{Q}$ coefficient is calculated according to the formula.

This is an objective indicator of group collaboration. Also, it is possible to measure subjective indicators: selfsatisfaction, satisfaction with partners, work, which already refers to group compatibility. One can record physical and physiological components of teamwork. These will be indicator energy costs spent for joint work.

The next use of cyber technologies is the modeling of the most complex group interaction (work of three or more teams) when solving a joint task, i.e. guessing a word, but a proverb or a saying. With this mode, one can observe how a separate group can stand out among the others to coordinate the joint activity, or how the spontaneous collaboration of all participants helps add letters, solve words and even proverbs. This is semantic activity.

In short, with these cybertrainings the most successful type of leaders hipor leader's specialization (the organizer, the generator of ideas, the performer-protocolist) is most clearly revealed. Moreover, leadership and successful management within and among groups shows "who is who". This is understandable for both personnel officers, being experts and observers, and the participants themselves. Apparently, any real manager will ask "What are the criteria for recruiting effective, average and unsuccessful groups?". There are several grounds for grouping, but 40-year research and practical experience shows that the main criteria are as follows:

group distributed by sex, mixed groups work better where there are fewer women than men $\mathrm{Q}=+0.44$, same-sex groups have negative Q;

group with mutual interests and liking, antipathies and indifferent (i.e. not choosing each other according to sociometric data) show the following tendency: those who are indifferent to each other work with the positive coefficient; less successful, but 
subjectively satisfied mutual-choosing each other and sociometric favorites of the team. In third place of the Q are those who treat each other negatively or are outcasts in the team. At the initial stage they can still somehow work together, but the interest in the joint activity gradually disappears.

group with a different behavioral pattern in the conflict by the method of K. Tomas. Orientationon competition, cooperation, avoidance and adjustment revealed significant differences in the success rate and the duration of effective teamwork. People focused on competition can be called "spiders", cooperation - "ants", and avoidance and adjustment - "flies".

A group of homogeneous "spiders" and "ants" are equally successful at the first stage. But longterm joint work results in the fact that "ants" remain successful for a very long period of up to three days (4 hours each day), while "spiders" gradually cool down, their motivation for teamwork decreases. The group of "flies" is the least successful, especially when it consists of same-sex participants. Groups consisting of both sexes are productive a bit more due to flirting, natural for men and women.
Finally, the development of cybertraining in 2010 allowed us to model a technology which can more adequately reflect the management, economic and psychological components of the individual-collective activity of people. What does it include? In general terms, cybertraining has already been described. However, there is always something to add. The momentum in to the creation of this option was a discussion at the Department of Psychology of Management. There is an intensive exchange between the universities of Russia and China. There was the delegation from China to St. Petersburg, and an interesting conversation took place. The author of the article asked the interpreter to share the opinion of the professor of the department. The opinion is the following. If we imagine a straight line (continuum) and on the one hand designate the individualism of Protestant America (the USA), and on the opposite side of the line China (tribal, collectivist), it turns out that Russia is somewhere between these poles. The answer of the Chinese was simple: "You were closer to us before, but where are you now?". My answer remained 
unspoken. The whole situation can be simulated in cybertraining.

Since work on the path is already known, it is easy to imagine three operating modes on the cybernometer.

The first option is the same, which has already been described, where all team members are responsible for the success of the work.

The second option suggests dividing the entire path into sectors where all group members will be responsible for a different sector, for example, from A to $\mathrm{B}, \mathrm{C}$, etc. (by the number of participants).

The third option means that responsibility for the actvity and, most importantly, for management belongs to the leaders of this joint activity.

\section{RESULTS}

The results of this cybertraining showed that efficiency increases from the first to the second mode, and reaches its peak during the third working mode. The result does not only show a coordination skill development. Control variants in the reverse order from the third, to the second and the first mode, confirm the correctness of the conclusions.

However, when all the participants were offered to choose one of the modes, it turned out that the students of the first courses preferred the first option more, the second one was less attractive, and finally, one few students chose the third mode which we called the managerial mode. Another result was obtained during the cybertraining with managers who already occupied their top positions. They claimed that they preferred the third mode, or at least the second one. They also added that they would work with greater efforts in the third mode if they were promised a reward. Thus, if there is a reward, motivation increases, and the trend of success differences increases as well, i.e. Q showed just a stunning difference between the collective, individual and managerial working modes.

The first case represents the motivation of the primitive communal, collective self-organization, where every person is rewarded the same way; it could be a gift in the form of an interesting and rare book or money. The second option assumes the division of responsibility for a separate sector. Motivation increases since a person gets a prize for the best results in his area of work. The third option shows even more valuable management, where the best 
leader tries to organize a group to get the best reward. It turned out that from an occasional discussion with the Chinese, the last variant of group interaction was created: social-collectivist, individualpossessive and managerial (socialdemocratic).

\section{Conclusion}

In general, "cybertraining of successful leadership and management" has shown its efficiency with both cosmonauts, flight crews, tank crews, nuclear power plants operators and other "socio technical systems", teams of athletes ranging from boat's crew to hockey players, football players, volleyball players, basketball players, etc.

\section{Recommendations}

Over the last 5 years, cybertraining of successful leadership and management has been and is being introduced in corporate games and trainings, educational process of schools, lyceums, universities of Russia and other countries (Belarus, Ukraine, Kazakhstan, Finland).

The results of the study confirm the viability and reasonability of the method and its effectiveness during individual and group selection; most importantly the method can be used for teambuilding or successful managers identification.

\section{References}

Berne E. Games People Play: The Psychology of Human RelationshipsM.: Eksmo, 2013. P. [Bern E. Igry, v kotorye igrayut lyudi. Lyudi, kotorye igrayut $\mathrm{v}$ igry]

Bykhovskiy B.E. Schopenhauer. M.: Mysl', 1975.P. [Bykhovskiy B.E., Shopengauer]

KomteA. Course of positive philosophy in six volumes. M., 1971. T. 3. P. [Kont O. Kurs pozitivnoj philosophii $\mathrm{v}$ shesti tomah]

Mayers D. Social psychology. St. Petersburg: Peter, 2000. P.[Mayers D. Sotsial'naya psikhologiya]

Obozov N.N. Human psychology. From body to soul. SPb.: Shape, 2001.P. [Obozov N.N. Psikhologiya cheloveka. Ot tela k dushe]

Selye H. Stress without distress. Moscow: Progress, 1979. P. [Sel'e G. Stress bez Distressa]

Turgenev I.S. Complete works and letters in thirty volumes. Moscow: Nauka, 1980. Vol. 5.P. [Turgenev I.S. 
Polnoe Sobranie Sochineniy i pisem v tridsati tomah]

Freud S. Psychology of the unconscious: Collection of works / compiled, edited by M. G. Yaroshevsky. Moscow: Education, 1990. P. [Freid Z. Psikhologiya bessoznatelnogo]

Freud S. The interpretation of dreams. SPb.: ABC, 2012.P. [Freid Z. Tolkovanie snovideniy]

Fromm E. Man for Himself: An Inquiry into the Psychology of Ethics. Minsk: Collegium, 1992.P.[Fromm E. Chelovek dlya samogo sebya. Issledovanie psikhologicheskih problem etiki]

Chernyshevsky N.G. What is to be done? L.: Science, 1975.P. [Chernyshevskiy N.G. Chto Delat'?]

Chernyshevsky N.G. Collected works in five volumes. M.: True, 1974. T. 4. P.[Chernyshevskyi N.G. Sobranie sochineniy v pyati tomah]

Abrams D., Vyver van de J., Pelletier J., Cameron L. Children's prosocial behavioral intentions towards outgroup members // British Journal of Developmental Psychology. 2015. Vol. 33. N 3. Pp. 277-294.

Bockler A., Tusche A., Singer T. The Structure of Human Prosociality // Social Psychological and Personality Science. 2016. Vol. 7. N 6. Pp. 530-541.
Brahm T., Kunze F. The role of trust climate in virtual teams // Journal of Managerial Psychology. 2012. Vol. 27. N 6. Pp.595-614.

Britton J.J. Expanding the coaching conversation: group and team coaching // Industrial and Commercial Training. 2015. Vol. 47. N 3. Pp.116-120.

Clutterbuck D. Time to focus coaching on the team // Industrial and Commercial Training. 2013. Vol. 45. N 1. Pp.18-22. Feldmanhall O., Dalgleish T., Evans D. Moral Chivalry // Social Psychological and Personality Science. 2016. Vol. 7. N 6. Pp. 542-551.

Gevers J., Driedonks B., Jelinek M., van Weele, A. Functional diversity appropriateness: Members' and managers' differential perceptions // Journal of Managerial Psychology. 2015. Vol. 30. N 6. Pp.709-725.

Gorbunova V.V. Success in teamwork: reflexive-value characteristics // Psychology journal (Psikhologicheskii zhurnal). 2014.Vol. 35. N 2. Pp. 33-44.

Halali E., Dorfman A., Jun S. More for Us or More for Me? Social Dominance as Parochial Egoism // Social Psychological and Personality Science. 2018. Vol. 9. N 2. Pp. 254-262.

Hauschildt K., Konradt U. Selfleadership and team members' work role 
performance // Journal of Managerial Psychology. 2012. Vol. 27. N 5. Pp. 497517.

Hawley P. Ontogeny and Social Dominance: A Developmental View of Human Power Patterns //Evolutionary Psychology. 2014. Vol. 12. N 2.P.

Hayward P. Team cognition using collaborative technology: a behavioral analysis // Journal of Managerial Psychology. 2013. Vol. 28. N 1. Pp.3854.

Kimbler K., Margrett, J. Older adults' interactive behaviors during collaboration on everyday problems: Linking process and outcome // International Journal of Behavioral Development. 2009. Vol. 33. N 6. Pp. 531-542.

Lin-Healey F., Small D. Nice Guys Finish Last and Guys in Last Are Nice // Social Psychological and Personality Science. 2013. Vol. 4. N 6. Pp. 692-698 Michaels J., Vallacher R., Liebovitch L. Volatile Psychological Dynamics in Social Interactions // Social Psychological and Personality Science. 2013. Vol.4 N 6. Pp. 705-713. O'Brien D.T. An Evolutionary Model of the Environmental Conditions that Shape the Development of Prosociality //
Evolutionary Psychology. 2014. Vol. 12. N 2.P.

Raine A. The Selfishness Questionnaire: Egocentric, Adaptive, and Pathological Forms of Selfishness// Journal of Personality Assessment. 2018. [Electronic resource]Access mode:

URL:

https://www.tandfonline.com/doi/full/10 $.1080 / 00223891.2018 .1455692$

Rao M.S. Collaborate to build effective teams to achieve organizational excellence and effectiveness // Industrial and Commercial Training. 2016. Vol. 48. N 1. Pp. 24-28 